\title{
The Effect of Citric Acid on Physicochemical Properties of Hydrophilic Carboxymethyl Starch-Based Films
}

\author{
Katarzyna Wilpiszewska ${ }^{1}\left[\right.$ ] Adrian Krzysztof Antosik $^{2} \cdot$ Magdalena Zdanowicz $^{1}$
}

Published online: 8 April 2019

(c) The Author(s) 2019

\begin{abstract}
The carboxymethyl starch-based films in a presence of citric acid were prepared by casting technique. The influence of citric acid content on physicochemical properties of obtained hydrophilic films were evaluated (solubility in water, moisture absorption, mechanical and thermal properties). The crosslinking of starch derivative chains has been confirmed by FTIR spectroscopy, however, an excess of citric acid could cause hydrolysis of carboxymethyl starch chains. The best mechanical performance has been noted for the system containing $30 \mathrm{wt} \%$ (the highest tensile strength as well Young modulus $160 \mathrm{kPa}$ and $650 \mathrm{kPa}$, respectively) as well as the highest $\mathrm{T}_{\mathrm{g}}$ (ca. $58^{\circ} \mathrm{C}$ ). Additionally for the mentioned system the lowest solubility in water has been determined.
\end{abstract}

Keywords Carboxymethyl starch $\cdot$ Citric acid $\cdot$ Polysaccharide film

\section{Introduction}

In the last decade preparing biodegradable films basing on biorenewable polymers has been intensively studied. Among them polysaccharides, such as starch, cellulose and chitosan are important materials.

Carboxymethyl starch (CMS) is an anionic starch derivative. Unlike native starch it is soluble in cold water, exhibits no tendency to retrogradation (recrystallization) and higher thermal stability. Because it is non-toxic, biodegradable, and biocompatible with human body it found application in many areas of interests, such as pharmacy and medicine, food industry, cosmetics, environmental protection and others [1]. CMS is prepared in so-called Williamson reaction, between starch and monochloroacetic acid or its sodium salt form in a present of strong alkali [2]. Performing modification in an organic solvent prevents starch granules from

Katarzyna Wilpiszewska

kwilpi@zut.edu.pl

1 Faculty of Chemical Technology and Engineering, Polymer Institute, West Pomeranian University of Technology, ul. Pulaskiego 10, 70-322 Szczecin, Poland

2 Faculty of Chemical Technology and Engineering, Institute of Organic Chemical Technology, West Pomeranian University of Technology, ul. Pulaskiego 10, 70-322 Szczecin, Poland disruption and allows to wash out the side products easily. The physicochemical properties of CMS (i.e. ability to swell in cold water, thermal stability, viscosity of aqueous solution as well as film forming ability) depend greatly on its degree of substitution (DS), i.e. the average number of substituents per anhydroglucose group [2].

Crosslinking of CMS has been performed to produce hydrogels for potential application in metal ions removal from water [3, 4], as pharmaceutical gelling agent and emulsion stabilizer [5], tablet disintegrant [6], or for drug delivery systems $[7,8]$. The crosslinking agents were dichloroacetic acid [4, 5], phosphorous oxychloride [3], epichlorohydrin [9], sodium trimetaphosphate [10], or polyfunctional carboxylic acids [11].

Citric acid is a low cost organic acid widely used in food industry. It contains three carboxylic groups that could react with the hydroxyl groups of starch molecules through the formation of esters [12]. It was used as compatibilizer in the starch-polymer blends, e.g. starch-polyester [13] or starch/poly(lactic acid) [14], as well as crosslinking agent for starch-based films [15], starch-carboxymethyl cellulose films [16], starch-hydroxypropyl methylcellulose [13], or starch poly(vinyl alcohol) films [17]. Unreacted CA in starch matrix can work as a plasticizer, lowering the $\mathrm{T}_{\mathrm{g}}$ value [15]. However, when crosslinking of starch occurred the improvement of mechanical properties (tensile strength) could be noted [17]. 
There are only a few publication on carboxymethyl starch-based films. Kittipongpatana et al. [18] prepared starch derivative-based films using CMS with low degree of substitution (0.2-0.4), without plasticized addition, by casting technique at $60{ }^{\circ} \mathrm{C}$ for $17 \mathrm{~h}$. Prepared films were soluble in water, and their elasticity, softness as well as integrity dependent greatly on amylose content. Sodium carboxymethyl mungbean starch plasticized with propylene glycol, poly(ethylene glycol) and glycerol has been applied as an aqueous-based coating agent for tablets [19]. CMSbased films containing acid-amide cross-linkages have been prepared in a presence of zein protein [20]. Interestingly, a small amount of zein protein has been found on the film surface, resulting in surface hydrophobicity increase (hot water insolubility and low water vapor permeability). Medium substituted CMS (DS 0.4-0.6) were used for edible films preparation [21]. The mixture of up to four plasticizers (glycerol, sorbitol, mannitol, and xylitol) was used. Obtained films dissolved in water and their mechanical properties as well as solubility depended on type and amount of the plasticizing mixture.

Although preparing some CMS systems containing CA has been recently reported [22] the effect of CA has not been evaluated yet.

The aim of this study was to prepare hydrophilic CMS based films with CA by casting technique, and to evaluate the effect of CA content on the physicochemical properties (solubility in water, moisture absorption, mechanical and thermal properties) of obtained films. Such hydrophilic films could be used in agriculture, e.g. for seed tapes production as their main role is retaining humidity, seed protection and germination improvement.

\section{Materials and Methods}

\section{Materials}

For preparation of CMS with high degree of substitution potato starch (Nowamyl S.A. Poland), monochloroacetic acid (a.g.), methanol (pure) and 2-propanol (pure)-the products of Chempur (Poland) were used. Sodium hydroxide (p. a.) was the product of POCH (Poland).

For preparation of CMS-based films glycerol (pure, Chempur, Poland) and citric acid monohydrate (p.a., Chempur, Poland) were applied.

\section{Preparation of Carboxymethyl Starch with High Degree of Substitution}

CMS with high degree of substitution 0.8 was prepared according to the method described elsewhere [22]. Modification of potato starch was carried out in a batch reactor equipped with a mechanical stirrer, a thermocouple, and a capillary tube supplying nitrogen to the reaction system. Starch (13.6-14 wt\% moisture) was etherified in isopro$\mathrm{panol} /$ water in a one-step process. In the batch reactor MCA was dissolved in isopropanol, and then aqueous solution of $\mathrm{NaOH}$ was added (the molar ratio of MCA/polysaccharide recurrent unit was 2, whereas $\mathrm{NaOH} / \mathrm{MCA} 2.2$ ). When the mixture became white and homogeneous, starch and remaining $\mathrm{NaOH}$ were introduced. Obtained product was filtered, neutralized with glacial acetic acid, washed five times in $80 \mathrm{wt} \%$ methanol aqueous solution, then once again in methanol and dried in the air [22].

\section{Determination of Degree of Substitution}

DS was measured according to method described by Kessel [23]. The CMS sample was moisturized by $1 \mathrm{~mL}$ of ethanol and dissolved in $50 \mathrm{~mL}$ of distilled water. Subsequently, buffer was added $\left(\mathrm{NH}_{4} \mathrm{Cl}\right.$ aqueous solution, $\left.20 \mathrm{~mL}\right)$, neutral $\mathrm{pH}$ was adjusted, and then the whole mixture was poured into a measuring flask $(250 \mathrm{~mL})$ with $50 \mathrm{~mL}$ of $\mathrm{CuSO}_{4}$ solution. After $15 \mathrm{~min}$, the measuring flask was filled up with water and the whole content was filtered. Filtrate was titrated with EDTA solution using murexide as an indicator.

\section{Preparation of Carboxymethyl Starch-Based Films}

In the glass reactor citric acid $(15,30,45$ or $60 \mathrm{wt} \%$ on the basis of CMS), $2 \mathrm{~g}$ glycerol and $100 \mathrm{~mL}$ distilled water were placed. Subsequently, $3 \mathrm{~g}$ dry CMS was added and mixed intensively at room temperature until homogeneity (ca. $0.5 \mathrm{~h}$ ). The final mixture was poured into PTFE mold and dried for $48 \mathrm{~h}$ at $60^{\circ} \mathrm{C}$. Obtained films (thickness 200-300 $\mu \mathrm{m}$ ) were peeled off and used for further tests.

\section{Methods}

\section{FTIR Spectroscopy}

FTIR analyses of the films were performed using Nexus FTIR Spectrometer Thermo Nicolet with Golden Gate ATR attachment. The resulting spectra were converted using the software OMNIC. CMS-based film before measurement was immersed in distilled water for $24 \mathrm{~h}$ at room temperature to remove residual CA and dried at $50{ }^{\circ} \mathrm{C}$ [24].

\section{Surface Morphology}

The surface morphology of CMS-based films was observed using laser scanning microscopy (LSM), model VK 9700 (Keyence, Japan) equipped with a violet laser source (wavelength $408 \mathrm{~nm}$ ) and a pin hole confocal optical system. During LSM analysis the field of the microscope was scanned 
Fig. 1 FTIR spectra of CA, CMS and CMS-based film containing $30 \mathrm{wt} \% \mathrm{CA}$

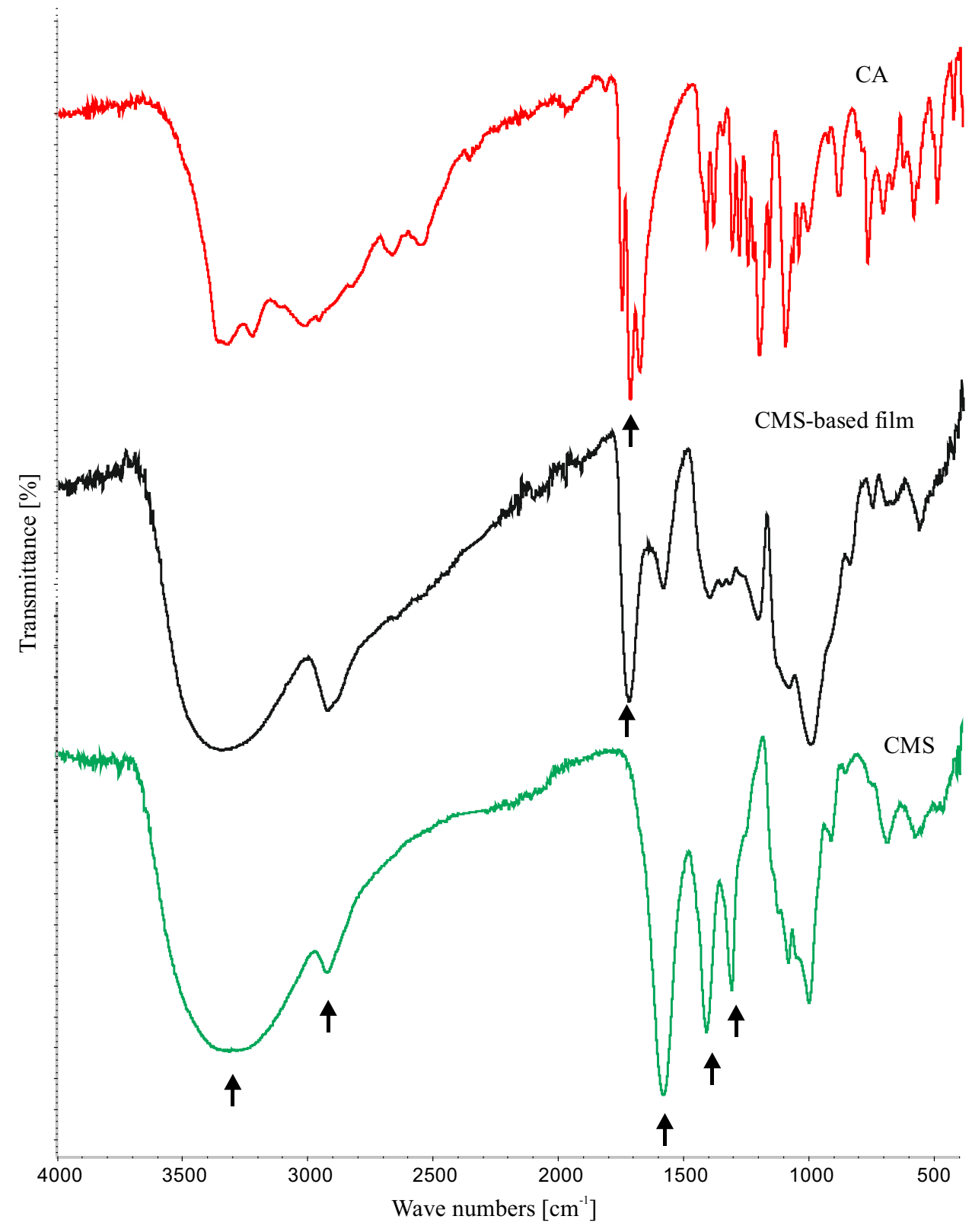

using a laser beam and an X-Y scan optical system. While moving the objective lens in the Z-axis and repeatedly scanning the measured area the reflecting light intensity based on the $\mathrm{Z}$ position was obtained. Application of the pinhole confocal optical system allowed to eliminate the reflecting light from points other than the peak (focal point) entirely, what assured high measurement accuracy. For the measurements $\times 400$ magnification was applied. The surface roughness parameters $\mathrm{Rz}$ and $\mathrm{Ra}$ were calculated using the VK Analyzer software. Each measurement was the average of three profiles with the interval of $20 \mu \mathrm{m}$.

\section{Solubility in Water and Moisture Absorption Tests}

Solubility in water was evaluated for each film. Three samples $(1.5 \mathrm{~cm} \times 1.5 \mathrm{~cm})$ were prepared and placed for 2 weeks in a desiccator to dry. Dry samples were weighed and transferred to test tubes filed with $50 \mathrm{~mL}$ of distilled water. After $24 \mathrm{~h}$ samples were dried and weighed. Solubility was calculated using equation [25]:

$T S M=\frac{M_{1}-M_{2}}{M_{1}} \times 100 \%$

where TSM-total soluble mater (in water) [\%]; $\mathrm{M}_{1}$-mass of dry sample [g]; $\mathbf{M}_{2}-$ mass of sample after drying $[\mathrm{g}]$. 
<smiles>O=C(O)CC(O)(CC(=O)O)C(=O)O</smiles><smiles>[R][X][R]([H])([H])C(=O)O</smiles>

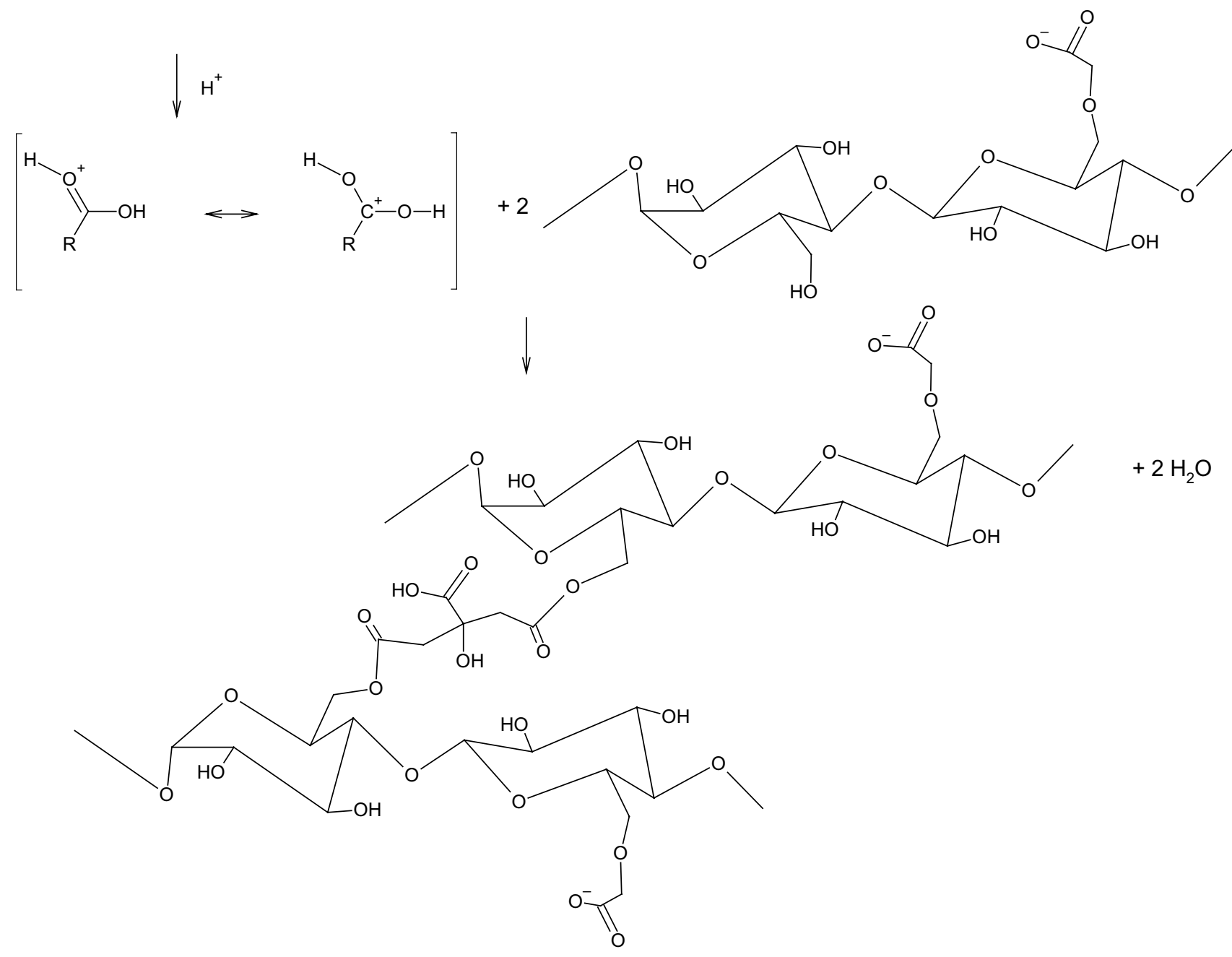

Fig. 2 Scheme of CMS crosslinking reaction with CA

Moisture absorption test were performed for each film as following. Three samples $(1.5 \mathrm{~cm} \times 1.5 \mathrm{~cm})$ were prepared and placed for 2 weeks in a desiccator to dry. Dry samples were weighed and subsequently transferred to a climatic chamber $\left(55 \pm 2 \%\right.$ humidity, $\left.25 \pm 2{ }^{\circ} \mathrm{C}\right)$. The weight of tested samples was controlled $3,5,7,24,48$, and $72 \mathrm{~h}$ after placing them in a climate chamber. Moisture absorption was calculated using equation [25]:

$A_{t}=\frac{M_{t}-M_{0}}{M_{0}} \times 100 \%$ where $\mathrm{A}_{\mathrm{t}}$-moisture absorption after time t [\%]; $\mathrm{M}_{0}$-mass of dry sample [g]; $\mathrm{M}_{\mathrm{t}}-$ mass of sample after time $\mathrm{t}: 3,5,7$, 24,48 and $72 \mathrm{~h}[\mathrm{~g}]$.

\section{Mechanical Properties of CMS-Based Films}

Mechanical properties were determined using a tensile tester (Instron 4026, Instron Corporation) equipped with $1 \mathrm{kN}$ load cell. The specimens $(10 \mathrm{~mm} \times 100 \mathrm{~mm}$ strips $)$ were conditioned at $\mathrm{RH}=55 \%$ for $24 \mathrm{~h}$. The initial grip separation and cross-head speed were $50 \mathrm{~mm}$ and $1 \mathrm{~mm} / \mathrm{min}$, respectively. The true strain $\varepsilon$ was determined by $\varepsilon=\ln \left(\mathrm{L} / \mathrm{L}_{0}\right)$, where $\mathrm{L}$ and $\mathrm{L}_{0}$ were the length during the test and the length at 


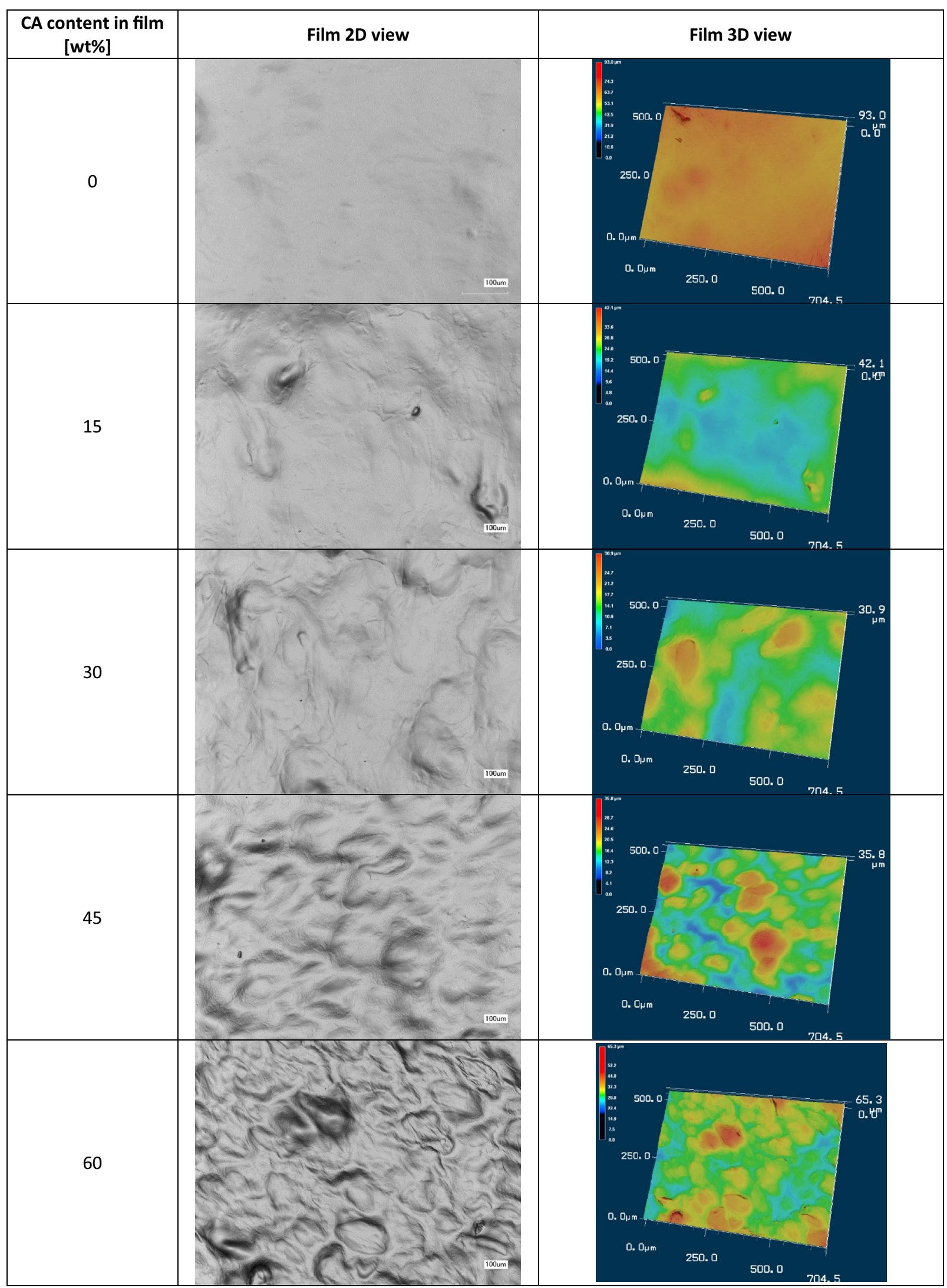

Fig. 3 The laser scanning microscopy topographical and 3D images of CMS-based films with various CA content 
Table 1 The roughness parameters for CMS-based films with various CA content

\begin{tabular}{lrl}
\hline CA content in CMS/CA & \multicolumn{2}{l}{ Roughness $(\mu \mathrm{m})$} \\
\cline { 2 - 3 } films (wt\%) & $\mathrm{Rz}$ & $\mathrm{Ra}$ \\
\hline 0 & $6.553 \pm 0.052$ & $1.375 \pm 0.012$ \\
15 & $7.885 \pm 0.046$ & $1.792 \pm 0.016$ \\
30 & $7.529 \pm 0.061$ & $1.882 \pm 0.019$ \\
45 & $11.945 \pm 0.073$ & $2.419 \pm 0.027$ \\
60 & $12.784 \pm 0.081$ & $2.784 \pm 0.031$ \\
\hline
\end{tabular}

zero time, respectively. The true stress $\sigma$ was calculated by $\sigma=F / S$, where $F$ was the applied load and $S$ the cross-section area. As $S$ was determined assuming that the total volume remained constant, so $\mathrm{S}=\mathrm{S}_{0} \mathrm{~L}_{0} / \mathrm{L}$, where $\mathrm{S}_{0}$ was the initial crosssectional area. The stress-strain curves were plotted and the tensile strength as well as Young modulus were determined from the slope of the strain region in the vicinity of $\sigma=\varepsilon=0\left([d \sigma / d \varepsilon]_{\varepsilon \rightarrow 0}\right)[26]$. The mechanical tensile data were averaged over ten specimens.

\section{Dynamic Mechanical Thermal Analysis (DMTA)}

DMTA analyses of the CMS films were determined using DMTA Q800 (TA Instruments). Measurements were performed using powder testing adaptor, at heating rate of $3{ }^{\circ} \mathrm{C} /$ min from -100 to $160{ }^{\circ} \mathrm{C}$, frequency $1 \mathrm{~Hz}$.

\section{Results and Discussion}

In Fig. 1 the FTIR spectra of CA, CMS, and CMS-based film were presented. The CMS-based films were washed to remove residual citric acid before testing [27]. For the unmodified CMS the absorption band between 3600 and
$3000 \mathrm{~cm}^{-1}$ and at $2900 \mathrm{~cm}^{-1}$ could be attributed to hydroxyl groups of CMS molecules and to $\mathrm{CH}_{2}$ stretching vibrations, respectively [28]. The strong peak at about $1600 \mathrm{~cm}^{-1}$ (intensity of this band strongly relates to high DS value) could be assigned to carboxylate (-COO-) [28], whereas at 1415 , and $1315 \mathrm{~cm}^{-1}$ to $\mathrm{CH}_{2}$ scissoring and $\mathrm{OH}$ bending vibrations, respectively [29].

For CA protonated carboxylic groups $\mathrm{C}-\mathrm{O}$ band at about $1700 \mathrm{~cm}^{-1}$ could be noted [30]. Whereas for CMS-based films the absorption band of carbonyl group was observed at $1715 \mathrm{~cm}^{-1}$ which is the confirmation of chemical linkages between starch and citric acid (crosslinking agent) via ester bonds.

The crosslinking reaction mechanism, i.e. formation of intermolecular diesters between carboxylic acid groups and the hydroxyl groups is shown in Fig. 2 (for the sake of clarity the CMS with degree of substitution 0.5 is given). It is known, that the ester bond formation is catalyzed by low $\mathrm{pH}$ or Lewis acids, as at higher $\mathrm{pH}$ fewer hydrogen ions for protonation are available resulting in lower esterification

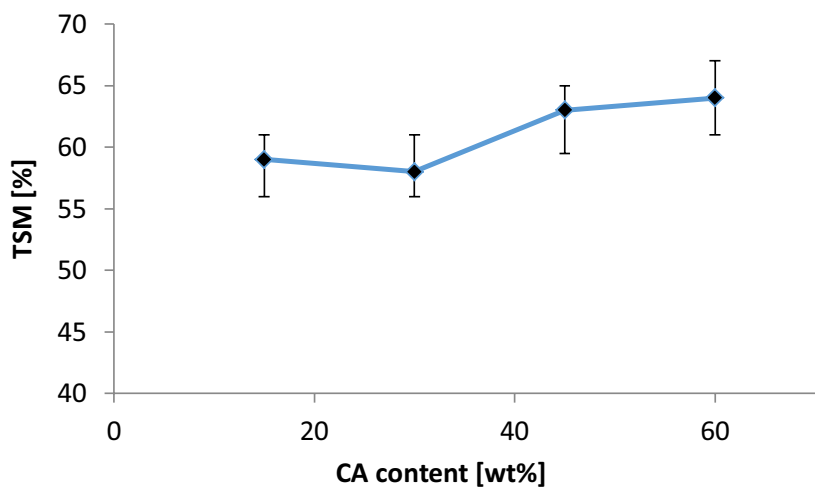

Fig. 5 Solubility in water of CMS-based films with various CA content
Fig. 4 Moisture absorption of CMS-based films with various CA content

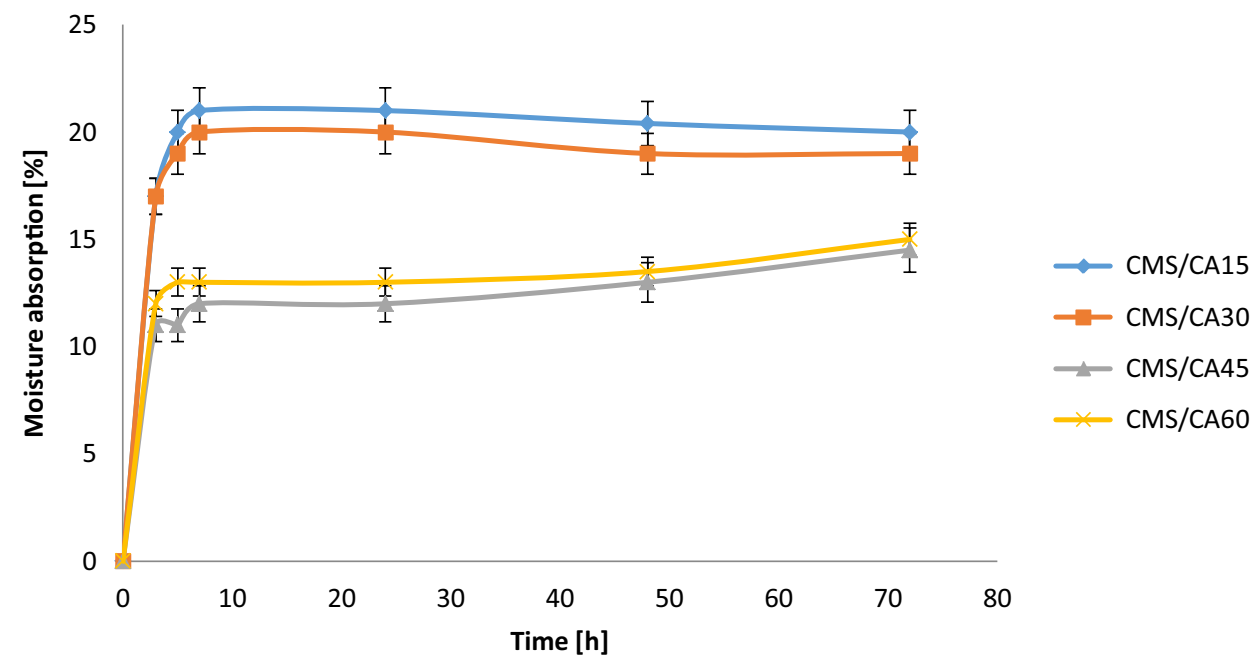


efficiency [15]. Although the carboxymethyl groups are more accessible (more spatial and remote from the polymer backbone), the esterification reaction between carboxyl groups of CA and hydroxyl of CMS is possible. Because of steric repulsion, it is unlikely that all carboxyl groups of CA could react with CMS.

The morphology of prepared CMS/CA films was presented in Fig. 3. Additionally, the 3D topographical views were also presented. With CA content in the system the film surface is more developed and differentiated. It was confirmed by the surface roughness parameters: Rz (maximum roughness) and $\mathrm{Ra}$ (arithmetic mean roughness) — presented in Table 1. An increase of surface roughness parameters (from ca. 6.5 up to ca. 12.8, and from ca. 1.4 up to ca. 2.8, for $\mathrm{Rz}$ and $\mathrm{Ra}$, respectively) indicated limited homogeneity of the systems with higher CA amount.

In Fig. 4 the moisture absorption of CMS-based films as a function of CA content was presented. For all obtained systems water absorption gradually increased and after $7 \mathrm{~h}$ tended to the balance. By incorporating various amounts of CA into CMs matrix it was possible to reduce the water absorption, what could be explained by higher crosslinking density (crosslinked bridges together with naturally occurring intermolecular bonds increase water resistibility) and correlates with FTIR results. Interestingly, the systems containing 45 and $60 \mathrm{wt} \% \mathrm{CA}$ exhibited reduced ability to water absorption than the films with lower CA content (up to ca. $8 \%$ after $72 \mathrm{~h}$ storage at RH 55\%). That could indicate that the systems containing higher CA amount exhibited higher crosslinking efficiency, however consecutive measurements results revealed other reason of this phenomenon.

The solubility in water of obtained CMS-based films as a function of CA content is presented in Fig. 5. The samples maintained their integrity, i.e., did not dissolve or break apart during solubility test, what indirectly confirms the crosslinking, as CMS is soluble in cold water. The systems containing lower CA amount, i.e. up to $30 \mathrm{wt} \%$ exhibited similar solubility, ca. 58\%. However, when higher CA dosage was applied the values of this parameter increased up to ca. 64\%. This indicates: (i) that some amount of CA could remain unreacted and its excess was washed out during this test and (ii) the possibility of CMS acidolysis (it has been reported that at very low $\mathrm{pH}$ the reduction of starch chains could occur $[16,31]$ ), that subsequently could lead to increased solubility in water. This elucidation could also explain the moisture absorption test results.

The mechanical properties of CMS-based films were characterized by tensile measurements at room temperature. In Fig. 6a-c the effect of citric acid content on mechanical properties was presented. Increasing CA content (from 15 up to $30 \mathrm{wt} \%$ ) the tensile strength and Young's modulus increase is observed: from 43 to ca. $160 \mathrm{kPa}$, and from 180 to ca. $650 \mathrm{kPa}$, respectively, what is probably the result of crosslinking of CMS chains providing better intermolecular interaction when compared to non-crosslinked system [27]. However, with higher CA concentration the values of both parameters dropped to ca. $70 \mathrm{kPa}$ and ca. $300 \mathrm{kPa}$, respectively. Similar effect, i.e. the tensile strength decrease and elongation at break increase with increasing amount of CA in the polymer matrix has been noted for corn starch-based films [27], thermoplastic pea starch composites [33] and for carboxymethyl cellulose/starch films [16]. Reddy and Young [27] for similar observation (corn starch-based films crosslinked with citric starch) presumed that it was a result of excess crosslinking and limited mobility of starch molecules leading to lower tensile strength. However, in such a case the value of Young modulus would not decrease. Thus, the explanation is that the excess of CA could cause
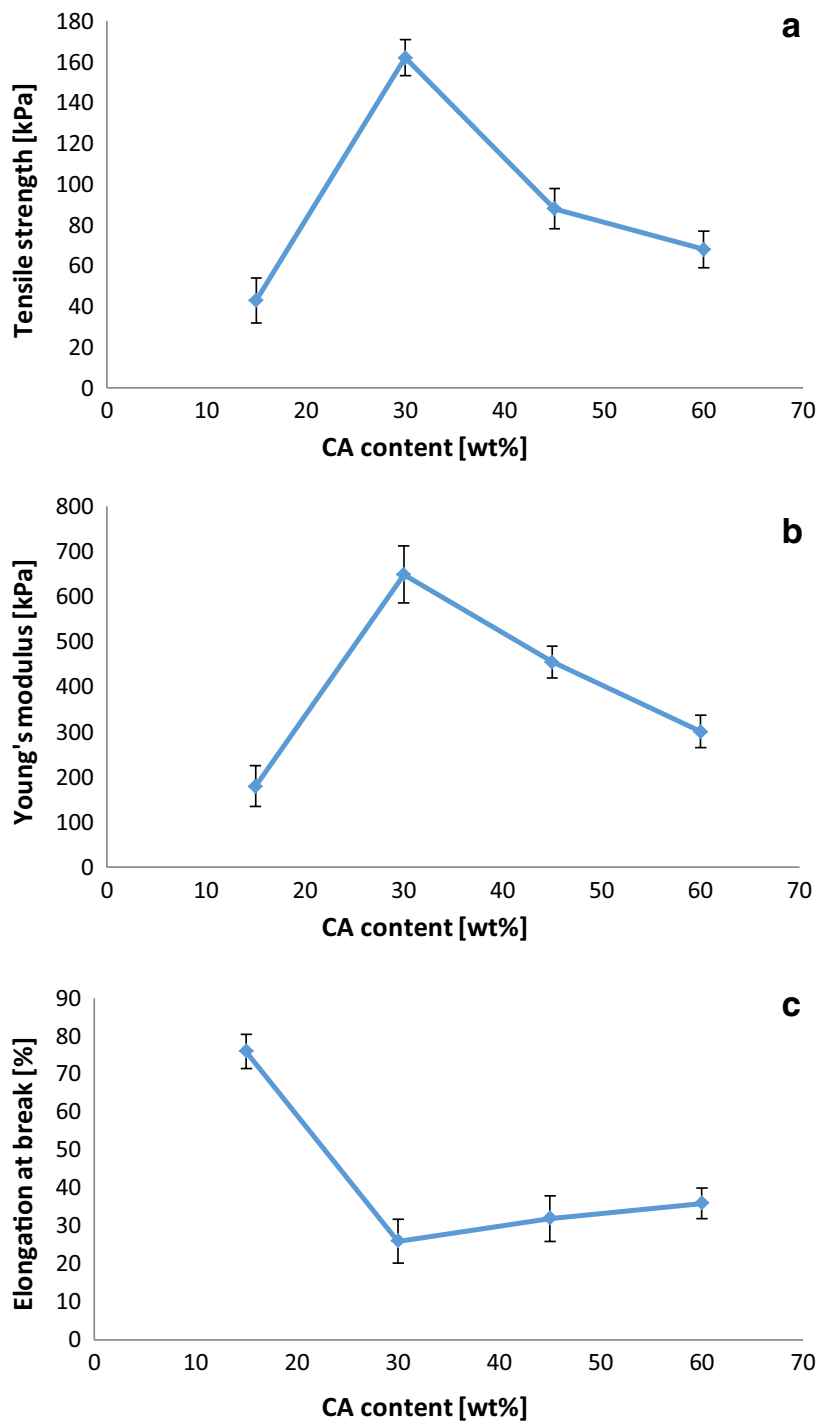

Fig. 6 Mechanical properties of CMS-based films with various CA content: a tensile strength, b Young's modulus, c elongation at break 


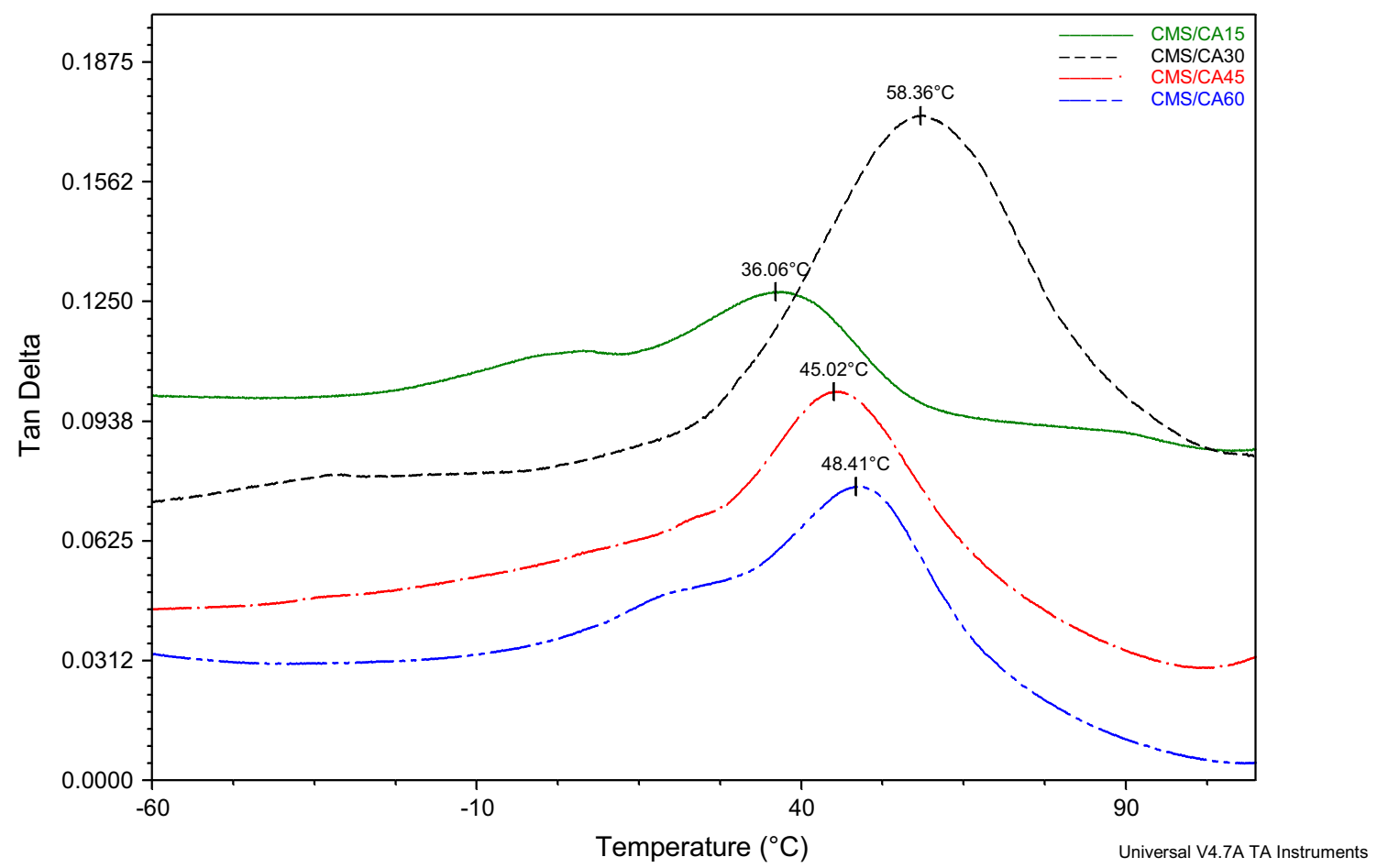

Fig. 7 DMTA curves of CMS-based films with various CA content

molecular weight reduction resulting in higher chain mobility [32] and subsequently lead to elongation at break increase (from 6 to ca. 36\% for the systems containing $30 \mathrm{wt} \%$ and $60 \mathrm{wt} \%$ CA, respectively). The attempts to obtain CMS films without using citric acid has been performed, however, the mechanical properties of such materials were too poor to be measured.

The evaluation of the loss factor ( $\tan \delta$ ) as a function of temperature for CMS/CA films was shown in Fig. 7. The loss factor is sensitive to molecular motion and its peak relates to the glass transition temperature [33]. The glass transition temperature increased with CA content in the CMS-based system, what could be related to crosslinking reaction. The lowest CA addition resulted in $\mathrm{T}_{\mathrm{g}}$ value ca. $36{ }^{\circ} \mathrm{C}$, whereas for the highest CA content ca. $48^{\circ} \mathrm{C}$. Interestingly the highest $\mathrm{T}_{\mathrm{g}}$ value, i.e. ca. $58{ }^{\circ} \mathrm{C}$ was noted for the system containing $30 \mathrm{wt} \% \mathrm{CA}$. The same system exhibited the highest tensile strength and Young modulus. That directly indicates for the highest crosslinking density when compared to other obtained system. The addition of up to $30 \mathrm{wt} \%$ citric acid lowered the mobility of the chains, thereby raising the $T_{g}$ and improving the thermal stability [32]. The DMTA results correlate to mechanical tests result indicating that the citric acid content in CMS-based films should not extent $30 \mathrm{wt} \%$.

\section{Conclusions}

The CMS-based films in a presence of citric acid were prepared. Citric acid in lower amount acted as a crosslinking agent for polysaccharide derivatives (confirmed by FTIR). However, an excess of CA could lead to CMS hydrolysis resulting in higher mobility of polysaccharide derivative chains. For the system containing $30 \mathrm{wt} \%$ the best mechanical performance has been noted (the highest tensile strength as well Young modulus $160 \mathrm{kPa}$ and $650 \mathrm{kPa}$, respectively) as well as the highest $\mathrm{T}_{\mathrm{g}}\left(\mathrm{ca} .58{ }^{\circ} \mathrm{C}\right)$. Additionally for the mentioned system the lowest solubility in water has been determined. All above let to conclude that for the most beneficial properties the citric acid content in CMS-based film should not exceed $30 \mathrm{wt} \%$. Prepared hydrophilic films could find application were retaining humidity performance is required, e.g. in agriculture.

Open Access This article is distributed under the terms of the Creative Commons Attribution 4.0 International License (http://creativeco mmons.org/licenses/by/4.0/), which permits unrestricted use, distribution, and reproduction in any medium, provided you give appropriate credit to the original author(s) and the source, provide a link to the Creative Commons license, and indicate if changes were made.

\section{References}

1. Spychaj T, Wilpiszewska K, Zdanowicz M (2013) Starch 65:22 
2. Fadzlina ZAN, Karim AA, Teng TT (2005) J Food Sci C 70:560

3. Kim BS, Lim ST (1999) Carbohydr Polym 39:217

4. Zdanowicz M, Spychaj T, Lendzion-Bieluń Z (2014) Int J Biol Macromol 71:87

5. Kittipongpatana N, Kittipongpatana OS (2015) Int J Pharm Pharm Sci 7:403

6. Kittipongpatana N, Janta S, Kittipongpatana OS (2011) Pak J Pharm Sci 24:415

7. Reis AV, Guilherme MR, Moia TA, Mattoso LHC, Muniz EC, Tambourgi EB (2008) J Polym Sci A 46:2567

8. Tan HL, Wong YY, Muniydandy S, Hashim K (2016) J Appl Polym Sci 133:43652

9. Chen YX, Zhong BH, Fang WM (2012) J Appl Polym Sci 124:5010

10. Kittipongpatana OS, Chaitep W, Kittipongpatana N (2010) Cereal Chem 87:214

11. Lawal O, Storz J, Storz H, Lohmann D, Lechner D, Kulicke WM (2009) Eur Polym J 45:3399

12. Ortega-Toro R, Jiménez A, Talens P, Chiralt A (2014) Carbohydr Polym 109:155

13. Garcia PS, Grossmann MVE, Shirai MA, Lazaretti MM, Yamashita F, Muller CMO, Mali S (2014) Ind Crops Prod 52:305

14. Chabrat E, Abdillahi H, Rouilly A, Rigal L (2012) Ind Crops Prod 37:238

15. Olsson E, Menzel M, Johansson C, Andersson R, Koch K, Järnström L (2013) Carbohydr Polym 98:1505

16. Ghanbarzadeh B, Almasi H, Entezami AA (2011) Ind Crops Prod $33: 229$

17. Shi R, Bi J, Zhang Z, Zhu A, Chen D, Zhou X (2008) Carbohydr Polym 74:763

18. Kittipongpatana OS, Chaitep W, Charumanee S, Kittipongpatana N (2006) CMU J Nat Sci 5:199
19. Kittipongpatana OS, Chaichanasak N, Kanchongkittipoan S, Panturat A, Taekanmark T, Kittipongpatana N (2008) Starch 58:587

20. Takahashi K, Ogata A, Yang WH, Hattori M (2002) Biochemistry 66:1276

21. Kim KW, Ko CJ, Park HJ (2002) J Food Sci: Food Eng Phys Prop $67: 218$

22. Wilpiszewska K, Antosik AK, Spychaj T (2015) Carbohydr Polym 128:82

23. Kessel H (1985) Starch 37:334

24. Wilpiszewska K, Czech Z (2014) Starch 66:660

25. Almasi H, Ghanbarzadeh B, Entezami AA (2010) Int J Biol Macromol 46:1

26. Angles MN, Dufresne A (2000) Macromolecules 33:8344

27. Reddy N, Yang Y (2010) Food Chem 118:702

28. Jiang Q, Gao W, Li X, Liu Z, Huang L, Xiao P (2011) Starch 63:692

29. Zdanowicz M, Spychaj T (2014) J Appl Polym Sci 131:40793

30. Yanli W, Wenyuan G, Xia L (2009) Carbohydr Res 344:1764

31. Shi R, Zhang Z, Liu Q, Han Y, Zhang L, Chen D, Tian W (2007) Carbohydr Polym 69:748

32. Azevedo VM, Dias MV, Borges SV, Costa ALR, Silva EK, Medeiros ÉAA, Soares NFF (2015) Food Hydrocolloids 48:179

33. Ma X, Chang PR, Yu J, Stumborg MM (2009) Carbohydr Polym $75: 1$

Publisher's Note Springer Nature remains neutral with regard to jurisdictional claims in published maps and institutional affiliations. 